\title{
Association between early childhood caries and intimate partner violence in 20 low- and middle-income countries: 2007-2017
}

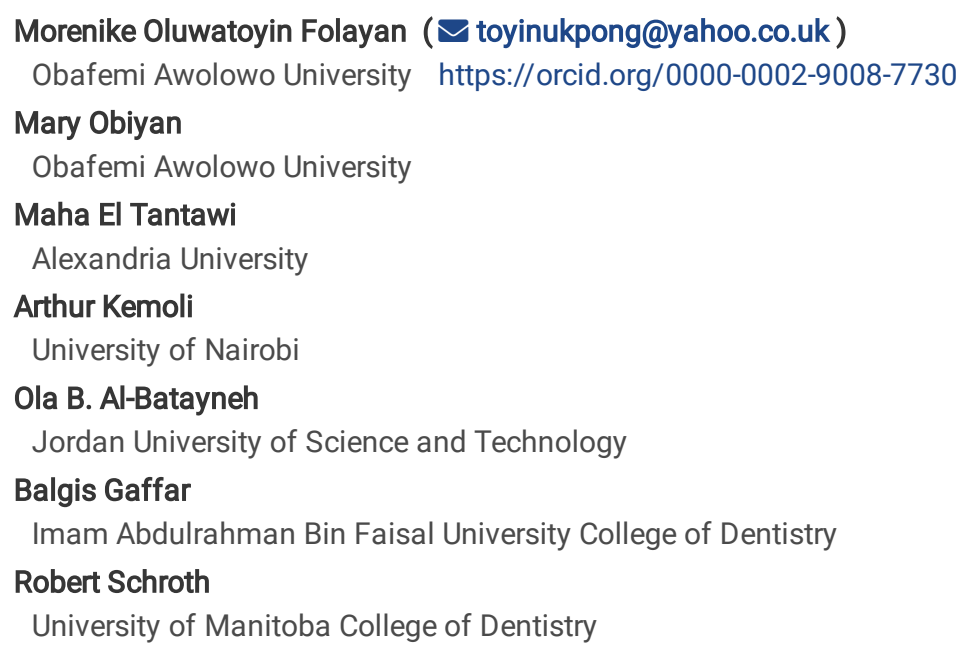




\section{Abstract}

Background: To determine the relationship between country level prevalence of interpersonal violence (IPV) and the prevalence of early childhood caries (ECC) in children aged 3-5-year-olds.

Method: This was an ecological study using extracted IPV (physical, sexual and emotional) and ECC data for 3-5-year-olds in 20 low- and middleincome countries for the period 2007-2017. Linear regression analysis was used to assess the relationship between the percentage of 3-5-year-old children with ECC (outcome variable) and the four IPV indicators (physical, sexual, emotional and a combination of the three). The model was adjusted for the country's Gross National Income GNI. Partial eta squared (as measure of effect size), regression coefficients, confidence intervals and $\mathrm{p}$ values were calculated.

Results: The strongest association was between ECC prevalence and exposure to physical violence (partial eta squared= 0.01 ), followed by exposure to sexual violence (partial eta squared=0.005), and exposure to all types of IPV combined (partial eta squared=0.001). Exposure to emotional violence had the weakest association with ECC (partial eta squared $<0.0001$ ). For $1 \%$ higher percentage of women reporting exposure to physical violence and percentage of women reporting all types of IPV combined, there was a $0.18 \%$ higher prevalence of ECC. For $1 \%$ higher prevalence of sexual violence, there was $0.22 \%$ higher ECC prevalence. For $1 \%$ higher prevalence of emotional violence, there was $0.04 \%$ higher ECC prevalence.

Conclusions: Countries with high prevalence of IPV will likely also have high prevalence of ECC. This needs further studies.

\section{Background}

Intimate partner physical, emotional and sexual violence (IPV) is a recognized threat to the health and rights of women globally [1, 2]. Global estimates indicated that about $30 \%$ of women have a history of IPV with this being highest in central (65.6\%) and western (41.8\%) sub-Saharan Africa, and South Asia (41.7\%) [3]. It is defined as the abuse that takes place between a couple who are either married or living together and may or may not have a child [4]. IPV not only has impact on maternal health and welfare [5], it also has a negative impact on the nutritional status of children of mothers affected by IPV who are more likely to be stunted [6-12]. This may be due to the negative impact on the mental health of affected women [13] with implications for poor nutritional care [14-16] and increased risk for stunting [6-8, 9, 10, 12]; and medical care access problems for children [12, 17-19].

Though several studies have established the negative association between maternal mental health and increased risk for ECC [20-24], there is very little known about the association between IPV and ECC. Lorber et al [25] studied children's exposure to domestic violence and the risk for ECC, and found no significant relationship between IPV and ECC though a positive trend was observed. However, in households where women were aggressive towards men, the risk for ECC was higher due to high exposure to cariogenic diets [26].

The social cognitive theory may explain the relationship between IPV and ECC. The theory recognizes that an individual's behavior, cognition, and environment reciprocally and dynamically influence one another [27]. Key social environmental and personal factors play roles in determining an individual's engagement in health promoting and disease preventing behaviors [28]. Self-efficacy is a central cognitive construct in the social cognitive theory that may predict and explain health behaviors and outcomes [29-31]. Thus, a person's belief or confidence in their ability to perform certain actions influences the decisions to perform these actions [32], including tooth brushing [33], which is a significant risk factor for poor oral hygiene and ECC [34]. IPV undermines self-efficacy of affected individuals [35, 36] who are mostly women [37] serving as care-takers for children [38]. IPV can therefore compromise the ability of women to care for children who are completely dependent on them for daily oral hygiene and accessing professional oral health care services.

The aim of this study was to determine the relationship between country level prevalence of IPV and the prevalence of ECC in children aged 3-5year-olds in countries where data on IPV and ECC are available. We conducted country-specific analysis in view of the evidence suggesting differences in the relationship between IPV and ECC [39].

\section{Methods}

This ecological study was based on IPV data extracted from the domestic violence module of the Demographic Health Survey, a nationally representative household survey that collects information on population-based indicators of health and nutrition in low-and middle-income countries (LMICs). The module includes questions on types and experiences of violence (physical, sexual and emotional) mostly perpetrated by the current or most recent husband/ partner [40]. The present study also used data on ECC collected by El Tantawi et al [42]. Data for both IPV and ECC were available in only 20 LMICs between 2007 and 2017.

Early childhood caries: Early childhood caries is identified in children < 72 months of age with one or more decayed (cavitated and non-cavitated), missing due to decay or filled primary tooth surfaces [42]. The data on ECC prevalence were extracted from World Health Organization Country Oral Health Profile database and studies published and indexed in MEDLINE, Scopus, Web of Science and Google Scholar covering the period 2007 to 
2017. No language filter was applied. The retrieved data were used to calculate the ECC prevalence for each country by dividing the number of children affected by ECC by the number of children examined and multiplying by 100 . In the present study, we used the prevalence of ECC for 3-5year-old children. Further details were reported in our previous paper [41].

Intimate partner violence: We investigated history of physical violence (the intentional use of physical force with the potential to cause injury or harm), sexual violence (any experience of unwanted or forced sexual activity and sexual coercion) and emotional violence (psychological abuse including humiliation, insults and intimidation) [43]. Self-reported maternal lifetime exposure to IPV was separated into four categories:

((i) physical violence only; (ii) sexual violence only; (iii) emotional violence only; and (iv) the three forms of IPV.

Confounders: Income level was reported to be associated with ECC [41] and IPV [3]. We adjusted for country income level based on the 2015 Gross National Income (GNI) per capita calculated using the World Bank Atlas method [44] since it was the latest available for the study period.

Statistical analysis: The datasets (ECC and IPV indicators) were matched by country. Analysis was restricted to only women selected and successfully interviewed in the DHS domestic module and those who were formerly or currently in union or living with a man at the time of survey. Statistics, including means and standard deviations (SD), were calculated for IPV indicators, ECC and GNI. Linear regression analysis was used to assess the relationship between the percentage of 3-5-year-old children with ECC (outcome variable) and each IPV indicator adjusted for GNI. Regression coefficients, 95\% confidence intervals (Cls), p values and partial eta squared (as measure of effect size) were calculated using SPSS version 22.0 (IBM Corp., Armonk, N.Y., USA). Significance level was set at 5\%.

\section{Results}

Data on ECC in 3-5-year-olds and IPV were available for 20 LMICS. These 20 countries included six low-income countries (30\%), 10 lower-middleincome countries (50\%) and four upper-middle-income countries $(20 \%)$. In view of the small number of countries with available data, analysis was conducted for all 20 countries collectively rather categorized by income level.

Table 1 lists the GNI, the percentage of 3-5 year old children with ECC, and the proportion of women in the country who reported (i) physical violence only; (ii) sexual violence only; (iii) emotional violence only; and (iv) all three forms of violence. The prevalence (SD) of ECC in 3-5-year-olds in these 20 countries was $62.20 \%$ (18.66) and the mean (SD) GNI $=6219.47$ (4083.99) US\$. The most commonly reported form of IPV was physical violence (25.46 (10.09)\%), followed by emotional violence (22.19 (9.90)\%), and lastly sexual violence (7.87 (6.18)\%). Overall, 4.91 (4.02)\% of the studied population reported experiencing all three forms of IPV. 
Table 1

Distribution of ECC and indicators of IPV in the 20 countries included in the study

\begin{tabular}{|c|c|c|c|c|c|c|c|c|}
\hline \multirow[t]{7}{*}{ ID } & \multirow[t]{7}{*}{ COUNTRY } & \multirow[t]{7}{*}{ GNI } & \multirow{2}{*}{$\begin{array}{l}\text { ECC } \\
\text { PREVALENCE }\end{array}$} & \multirow{2}{*}{$\begin{array}{l}\text { DEMOGRAPHIC } \\
\text { HEALTH SURVEY }\end{array}$} & \multirow{2}{*}{$\begin{array}{l}\text { COUNTRY } \\
\text { LEVEL }\end{array}$} & \multirow{2}{*}{$\begin{array}{l}\text { COUNTRY } \\
\text { LEVEL }\end{array}$} & COUNTRY & \multirow{2}{*}{$\begin{array}{l}\text { COUNTRY } \\
\text { LEVEL }\end{array}$} \\
\hline & & & & & & & LEVEL & \\
\hline & & & IN CHILDREN & NUMBER OF & PREVALENCE & PREVALENCE & PREVALENCE & PREVALENCE \\
\hline & & & AGED 3-5- & PARTICIPANTS AND & OF & OF SEXUAL & & OF ALL \\
\hline & & & YEAR-OLD & YEAR OF SURVEY & PHYSICAL & VIOLENCE & EMOTIONAL & FORMS OF \\
\hline & & & $\%$ & $\mathrm{n}$ (year) & VIOLENCE & $\mathrm{n}(\%)$ & VIOLENCE & VIOLENCE \\
\hline & & & & & n (\%) & & $\mathrm{n}(\%)$ & $\begin{array}{l}\text { COMBINED } \\
\mathrm{n}(\%)\end{array}$ \\
\hline 1 & Cambodia & 3300 & 78.8 & 3,499 (2014) & $536(15.3 \%)$ & $164(4.7 \%)$ & $790(22.6 \%)$ & $102(2.9 \%)$ \\
\hline 2 & Colombia & 13550 & 75.3 & $24,862(2010)$ & $\begin{array}{l}8,384 \\
(33.7 \%)\end{array}$ & $1,985(8.0 \%)$ & - & - \\
\hline 3 & $\begin{array}{l}\text { Congo, } \\
\text { DRC }\end{array}$ & 720 & 80.0 & $5,691(2013 / 14)$ & $\begin{array}{l}2,606 \\
(45.8 \%)\end{array}$ & $\begin{array}{l}1,448 \\
(25.4 \%)\end{array}$ & $2,073(36.4 \%)$ & $885(15.6 \%)$ \\
\hline 4 & Egypt & 10710 & 61.6 & 6,693 (2014) & $\begin{array}{l}1,590 \\
(23.8 \%)\end{array}$ & $267(4.0 \%)$ & $1,238(18.5 \%)$ & $193(2.9 \%)$ \\
\hline 5 & Gambia & - & 86.0 & $3,542(2013)$ & $784(22.1 \%)$ & $103(2.9 \%)$ & $592(16.7 \%)$ & $56(1.6 \%)$ \\
\hline 6 & India & 6030 & 52.1 & $66,013(2015 / 16)$ & $\begin{array}{l}18,680 \\
(28.3 \%)\end{array}$ & $4,372(6.6 \%)$ & $8.372(12.7 \%)$ & $2,220(3.4 \%)$ \\
\hline 7 & Kenya & 3070 & 64.2 & $4,519(2014)$ & $\begin{array}{l}1,609 \\
(35.6 \%)\end{array}$ & $529(11.7 \%)$ & $1,373(30.4 \%)$ & $346(7.7 \%)$ \\
\hline 8 & Kyrgyzstan & 3310 & 69.8 & 4,832 (2012) & $\begin{array}{l}1,283 \\
(26.6 \%)\end{array}$ & 201 (4.2\%) & $592(12.3 \%)$ & $112(2.3 \%)$ \\
\hline 9 & Myanmar & 4930 & 50.0 & $3,425(2015 / 16)$ & $575(16.8 \%)$ & $131(3.8 \%)$ & $544(15.9 \%)$ & $75(2.2 \%)$ \\
\hline 10 & Namibia & 10380 & 68.7 & 1,449 (2013) & 359 (24.8\%) & $106(7.3 \%)$ & $367(25.3 \%)$ & $70(4.8 \%)$ \\
\hline 11 & Nepal & 2500 & 61.5 & $3,826(2016)$ & $842(22.0 \%)$ & $297(7.8 \%)$ & $485(12.7 \%)$ & $162(4.2 \%)$ \\
\hline 12 & Nigeria & 5810 & 14.9 & $22,305(2013)$ & $\begin{array}{l}3,385 \\
(15.2 \%)\end{array}$ & $1,190(5.3 \%)$ & $4,477(20.1 \%)$ & $626(2.8 \%)$ \\
\hline 13 & Pakistan & 5320 & 60.0 & $4,085(2017 / 18)$ & $\begin{array}{l}1,004 \\
(24.6 \%)\end{array}$ & $184(4.5 \%)$ & $1,243(30.4 \%)$ & $135(3.3 \%)$ \\
\hline 14 & Peru & 12060 & 76.0 & $13,483(2012)$ & $\begin{array}{l}5,063 \\
(37.6 \%)\end{array}$ & $1,235(9.2 \%)$ & $4,187(31.1 \%)$ & $1,009(7.5 \%)$ \\
\hline 15 & Philippines & 8940 & 93.0 & $13,215(2017)$ & $\begin{array}{l}1,486 \\
(11.2 \%)\end{array}$ & 591 (4.5\%) & $2,903(22.0 \%)$ & $352(2.7 \%)$ \\
\hline 16 & Senegal & 2380 & 73.0 & $2,660(2017)$ & $546(20.5 \%)$ & 167 (6.3\%) & $357(13.4 \%)$ & $62(2.3 \%)$ \\
\hline 17 & $\begin{array}{l}\text { South } \\
\text { Africa }\end{array}$ & 12870 & 44.0 & $2,354(2016)$ & $356(15.1 \%)$ & $90(3.8 \%)$ & $451(19.2 \%)$ & $59(2.5 \%)$ \\
\hline 18 & Tanzania & 2630 & 37.3 & $15,194(2015 / 16)$ & $\begin{array}{l}5,512 \\
(36.3 \%)\end{array}$ & $\begin{array}{l}1,882 \\
(12.4 \%)\end{array}$ & $4,904(32.3 \%)$ & 1,328 (8.7\%) \\
\hline 19 & Uganda & 1820 & 41.0 & 7,536 (2016) & $\begin{array}{l}3,138 \\
(41.6 \%)\end{array}$ & $\begin{array}{l}1,710 \\
(22.7 \%)\end{array}$ & $3,141(41.7 \%)$ & $1,043(13.8 \%)$ \\
\hline 20 & Ukraine & 7840 & 56.7 & $2,453(2007)$ & $304(12.4 \%)$ & $59(2.4 \%)$ & $510(20.8 \%)$ & $49(2.0 \%)$ \\
\hline & Mean (SD) & $\begin{array}{l}6219.47 \\
(4083.99)\end{array}$ & $62.20(18.66)$ & $10,581(14,6667)$ & $\begin{array}{l}25.46 \\
(10.09 \%)\end{array}$ & 7.87 (6.18\%) & $22.19(9.90 \%)$ & $4.91(4.02 \%)$ \\
\hline
\end{tabular}

The Democratic Republic of Congo, a war-torn country, had the highest prevalence of physical (45.8\%) and the highest prevalence of the three forms of IPV combined (15.6\%). ECC prevalence in this country was also high (80\%). Sexual violence was highest in The Democratic Republic of Congo, followed by Uganda (25.4\%). The highest prevalence of emotional violence (41.7\%) and the second highest prevalence of all three forms of IPV combined (13.8\%) were in Uganda while the prevalence of ECC in Uganda was $41 \%$. 
Table 2 highlights the association between the percentage of 3-5 year-old children with ECC and the percentage of women with various types of IPV in the 20 LMICs after adjusting for GNI. The associations between ECC and each of the four categories of IPV were direct though nonsignificant. The strongest association was between ECC prevalence and exposure to physical violence (partial eta squared $=0.01$ ), followed by exposure to sexual violence (partial eta squared $=0.005$ ), and exposure to all types of IPV combined (partial eta squared $=0.001$ ). Reported exposure to emotional violence had the weakest association with ECC (partial eta squared $<0.0001$ ). Multiple linear regression analysis revealed that for every $1 \%$ higher percentage of women reporting exposure to physical violence and percentage of women reporting exposure to all types of IPV combined, there was a $0.18 \%$ higher prevalence of ECC. Also, for every $1 \%$ higher prevalence of sexual violence, countries had $0.22 \%$ higher ECC prevalence while for every $1 \%$ higher prevalence of emotional violence, countries had $0.04 \%$ higher ECC.

Table 2

Association between the percentage of 3-5 year-old children with ECC and the percentage of women with various types of IPV in 20 LMICs

\begin{tabular}{|llll|}
\hline Factors & Regression coefficient $(95 \% \mathrm{Cl})$ & P value & Partial eta squared \\
\hline Prevalence of physical violence & $0.18(-0.78,1.14)$ & 0.70 & 0.01 \\
\hline Prevalence of sexual violence & $0.22(-1.51,1.96)$ & 0.79 & 0.005 \\
\hline Prevalence of emotional violence & $0.04(-0.98,1.05)$ & 0.94 & $<0.0001$ \\
\hline Prevalence of all types of violence combined & $0.18(-2.57,2.93)$ & 0.89 & 0.001 \\
\hline Adjusted for country Gross national income, Cl: confidence interval & & \\
\hline
\end{tabular}

\section{Discussion}

This was the first study attempting to study the association between IPV and ECC using national data available from multiple countries around the world. This data suggest that in countries with higher proportion of women facing physical, sexual and emotional IPV, the prevalence of ECC is also higher. This relationship was not statistically significant likely due to the relatively few number of countries with available information from the Demographic Health Survey. In addition, the effect size observed is small though this not unexpected in view of the multifactorial nature of ECC and because IPV may be partly explained by the other major social determinant of health like education and income (for which we controlled in our analysis). The study finding however highlights an area for future research as there are indications that the global incidence of IPV has been on the increase [45]. The pathway for this association also needs to be further studied. This includes studying the possible link between IPV and culture, association between IPV and the presence/absence of national laws that protect women and their rights.

The study provides new information to strengthen existing evidence on how social context is associated with disease risks. Globally, the prevalence of ECC is high - it is the 10th most prevalent childhood illness [46]. Most of the efforts to address this problem have largely been limited to interventions aiming at altering biological and behavioral risk factors. Little attention has been paid to addressing the social determinants of health, which can impact the behavioral and biological risks.

Highlighting how IPV impacts negatively on the oral health of pre-school children has two implications: the percentage of children with ECC in LMICs may be associated with care-givers' risk of exposure to IPV. Identification of caregivers experiencing IPV may help with identifying child at risk for ECC at a young age. The first implication also reiterates the importance of integrated maternal and child health care as a cost-effective mechanism to manage diseases using the common risk approach [47]. There is currently very little evidence on approaches that promote the integration of maternal and child general healthcare with their - and especially the child's- oral health. As evidence emerges, it will be important to develop programs addressing maternal IPV and ECC in pre-school children as part of a general health screening process, especially in countries where the prevalence of IPV is high.

The second implication of the finding from this study is the challenge with planning macro-level interventions and using micro-level measures to assess success. Pending further confirmation from future studies, the association between IPV and ECC shown in this study may indicate the possibility of using ECC prevalence to monitor the success of country-level programs addressing IPV. However, there are very few countries that conduct regular national oral health surveys; and fewer that collect oral health data in pre-school children. Our findings highlight the importance of national ECC surveys so that this data can be used as an indirect, although may be less sensitive measure, of the impact of interventions to control IPV. Existing studies and reviews of the IPV and oral health literature reveal that the link between IPV and ECC is quite plausible [48]. Integrating early childhood promotion and ECC prevention messaging into women's shelters may be a first step to reduce the risk for caries and offer women practical methods to care for their children's oral health.

One of the strengths of the present study is the use of population-level data derived from the Demographic Health Survey thus ensuring data quality [49]. We used the data from 20 LMICs to provide insight to a phenomenon that if further explored, may shape policy and practice around ECC management [50]. Our study is however limited by the low number of included countries thereby challenging the generalizability of findings.

Page 5/8 
The low sample size was addressed by using partial eta squared, a measure of effect size, to compare the association of ECC with various forms of IPV and to decide on the importance of each variable, rather than using the $p$ values to determine the significance of the associations. Ensuring the availability of IPV data in other countries with different income levels may help develop a better understanding of the nature of the association between ECC and IPV.

Another limitation is that IPV data is based on self-reporting with the possibility of under-reporting due to social desirability bias [51]. However, this is the standard method used to obtain IPV statistics [52]. In addition, the study is ecological with potential for ecological fallacies [53, 54]; and its cross-sectional design has limited use in establishing a cause-effect relationship between ECC and IPV. We also only extracted data on IPV and women though there are evidence suggestive that both males and females may be victims of IPV [55, 56]; and IPV affecting men may be associated with the risk of ECC [26].

\section{Conclusions}

Despite these limitations, the study provides new insight into the possible association between ECC and IPV: physical, sexual and emotional violence were associated with ECC prevalence though the associations were not significant. Women's exposure to physical and sexual violence had greater association with the prevalence of ECC than other types of IPV.

\section{Abbreviations}

Cl Confidence Interval

ECC Early Childhood Caries

IPV Intimate Partner Violence

LMICs Low and Middle-Income Countries

GNI Gross National Income

\section{Declarations}

Ethics approval and consent to participate: Not applicable.

Availability of data and materials: Study related materials are public data. All study related data are included in the manuscript.

Funding: No grants was available for study implementation.

Consent for publication: Not applicable.

Competing interests: Morenike Oluwatoyin Folayan is a sectional editor with the BMC Oral Health. Maha Tantawi, Ola B Al-Batayneh and Arthur Kemoli are Associate Editors with the BMC Oral Health.

Authors contributions: Morenike Oluwatoyin Folayan conceptualized and designed the study, collected data, drafted the initial manuscript, and reviewed and revised the manuscript. Mary Obiyan extracted the IPV data from the Demographic Health Survey and reviewed and revised the manuscript. Maha El Tantawi, conducted the data analysis, critically reviewed and revised the manuscript for important intellectual content. Drs Schroth, Al-Batayneh, Gaffar, and Kemoli, were involved with the making decisions on the initial analyses plan, and reviewed and revised the manuscript for important intellectual content. All authors read and approved the final manuscript.

\section{References}

1. World Health Organization. Global and regional estimates of violence against women: prevalence and health effects of intimate partner violence and non-partner sexual violence. Geneva/ 2013. Available from:

http://apps.who.int/iris/bitstream/10665/85239/1/9789241564625_eng.pdf?ua=1;

2. World Health Organization. Intimate Partner Violence and Alcohol Fact Sheet. Geneva, Switzerland. WHO Press 2005.

3. Devries KM, Mak JYT, García-Moreno C, Petzold M, Child JC, Falder G, et al. Global health. The global prevalence of intimate partner violence against women. Science. 2013 Jun 28;340(6140):1527-8. http://dx.doi.org/10.1126/science.1240937 pmid: 23788730

4. American Psychological Association. Violence and the Family. Report of the APA Presidential Task Force on Violence and the Family. Washington, DC: APA, 1996. 
5. Sarkar NN. The impact of intimate partner violence on women's reproductive health and pregnancy outcome. J Obstet Gynaecol. 2008 Apr;28(3):266-71

6. Sobkoviak RM, Yount KM, Halim N. Domestic violence and child nutrition in Liberia. Soc Sci Med. 2012; 74(2):103-111.

7. Hasselmann MH, Reichenheim ME. Parental violence and the occurrence of severe and acute malnutrition in childhood. Paediatr Perinat Epidemiol. 2006;20(4):299-311.

8. Salazar M, Högberg U, Valladares E, Persson L-Å. Intimate partner violence and early child growth: a community-based cohort study in Nicaragua. BMC Pediatr. 2012;12(1):82.

9. Ackerson LK, Subramanian SV. Domestic violence and chronic malnutrition among women and children in India. Am J Epidemiol. 2008;167(10):1188-1196.

10. Rahman M, Poudel KC, Yasuoka J, Otsuka K, Yoshikawa K, Jimba M. Maternal exposure to intimate partner violence and the risk of undernutrition among children younger than 5 years in Bangladesh. Am J Public Health. 2012;102(7):1336-1345.

11. Levendosky AA, Graham-Bermann SA. Parenting in battered women: the effects of domestic violence on women and their children. J Fam Violence. 2001;16(2):171-192.

12. Rodríguez MA, Valentine J, Ahmed SR, Eisenman DP, Sumner LA, Heilemann MV, Liu H. Intimate partner violence and maternal depression during the perinatal period: a longitudinal investigation of Latinas. Violence Against Women. 2010;16(5):543-59.

13. Stewart RC. Maternal depression and infant growth: a review of recent evidence. Matern Child Nutr. 2007;3(2):94-107.

14. Anoop S, Saravanan B, Joseph A, Cherian A, Jacob KS. Maternal depression and low maternal intelligence as risk factors for malnutrition in children: a community based case-control study from South India. Arch Dis Child. 2004 Apr Apr;89(4):325-329.

15. Rahman M, Poudel KC, Yasuoka J, Otsuka K, Yoshikawa K, Jimba M. Maternal exposure to intimate partner violence and the risk of undernutrition among children younger than 5 years in Bangladesh. Am J Public Health. 2012;102(7):1336-1345.

16. Engle PL, Lhotska L. The role of care in programmatic actions for nutrition: designing programmes involving care. Food Nutr Bull. 1999;20(1):121-35.

17. Engle PL, Menon P, Haddad L. Care and nutrition: concepts and measurement. World Dev. 1999;27(8):1309-1337.

18. Black RE, Allen LH, Bhutta ZA, Caulfield LE, de Onis M, Ezzati M, et al.; Maternal and Child Undernutrition Study Group. Maternal and child undernutrition: global and regional exposures and health consequences. Lancet. 2008 Jan 19;371(9608):243-260.

19. dos Santos Pinto G, de Ávila Quevedo L, Britto Correa M, et al. Maternal depression increases childhood dental caries: A cohort study in Brazil. Caries Research 2016;51(1):17-25

20. Menon I, Nagarajappa R, Ramesh G, Tak M. Parental stress as a predictor of Early Childhood Caries among preschool children in India. International Journal of Paediatric Dentistry 2013;23(3):160-165

21. Themssl-Huber M, Freeman R, Humphris G, Macgillivray S, Terzi N. Empirical evidence of the relationship between parental and child dental fear: a structured review and meta-analysis. International Journal of Paediatric Dentistry 2010;20(2):83-101Elyasi M, Abreu LG, Badri P, et al. Impact of sense of coherence on oral health behaviors: a systematic review. PloS One 2015;10(8):e0133918.

22. Lyra MCA, Cruz M, Menezes V, Heimer MV. Association between sense of coherence and dental caries experience in adolescents. Brazilian Research in Pediatric Dentistry and Integrated Clinic 2015;15(1):235-41.

23. Lage CF, Fulgencio LB, Corrêa-Faria P, et al. Association between dental caries experience and sense of coherence among adolescents and mothers. International Journal of Paediatric Dentistry 2016;27(5):412-1

24. United Nations Children's Fund, World Health Organization, World Bank Group. Levels and trends in child malnutrition: Key findings of the 2018 Edition of the Joint Child Malnutrition Estimates. https://data.unicef.org/wp-content/uploads/2018/05/JME-2018-brochure-web.pdf. Published 2018.

25. Marsh S. Domestic abuse offences in London rise 63\% in seven years. February 2019. Available at: https://www.theguardian.com/society/2019/feb/27/domestic-violence-london-rise. Accessed 27 December 2019.

26. Vos T, Flaxman AD, Naghavi M, Lozano R, Michaud C, Ezzati M,et al. Years lived with disability (YLDs) for 1160 sequelae of 289 diseases and injuries 1990-2010: a systematic analysis for the Global Burden of Disease Study 2010. Lancet. 2012;380:2163-2196.

27. Lassi ZS, et al. Community-Based Care to Improve Maternal, Newborn, and Child Health. Reproductive, Maternal, Newborn, and Child Health: Disease Control Priorities, Third Edition (Volume 2). The International Bank for Reconstruction and Development / The World Bank 2016 Review

28. Weij C, Lang R, Lorenzett DL, Milaney K, Figueiredo R, Smith LB et al. The Relation Between Exposure to Intimate Partner Violence and Childhood Dental Decay: A Scoping Review to Identify Novel Public Health Approaches to Early Intervention. J Can Dent Assoc 2019;85:j5.

29. An assessment of the quality of data on health and nutrition in the DHS surveys, 1993-2003. DHS methodological reports 6. Macro International Inc. Calverton, Maryland, USA. 20098.

30. Deaton AS. The analysis of household surveys: a microeconometric approach to development policy. Washington: World Bank; 2018. Available from: http://www- 
wds.worldbank.org/external/default/WDSContentServer/WDSP/IB/1997/07/01/000009265_3980420172958/Rendered/PDF/multi_page.pdf.

31. Raphael K. Recall bias: a proposal for assessment and control. Int J Epidemiol 1987;16:167-70.

32. Visschers J, Jaspaert E, Vervaeke G. Social desirability in intimate partner violence and relationship satisfaction reports: an exploratory analysis. J Interpers Violence. 2017;32(9):1401-1420.

33. Schwartz S. The fallacy of the ecological fallacy: the potential misuse of a concept and the consequences. Am J Public Health, $1994 ; 84$ : 819 - 824.

34. Costa D, Hatzidimitriadou E, loannidi-Kapolou E, Lindert J, Soares JJ, Sundin Ö, et al. Male and female physical intimate partner violence and socio-economic position: a cross-sectional international multicentre study in Europe. Public health. 2016;139:44-52.

35. Costa D, Soares J, Lindert J, Hatzidimitriadou E, Sundin Ö, Toth O, et al. Intimate partner violence: a study in men and women from six European countries. International journal of public health. 2015;60(4):467-478. 